\begin{tabular}{lcl}
\hline Bentham OPEN & The Open Orthopaedics Journal \\
CrossMark & Content list available at: www.benthamopen.com/TOORTHJ/ & DOI: $10.2174 / 1874325001610010143$ \\
\hline
\end{tabular}

\title{
Adolescent Idiopathic Scoliosis
}

\author{
Muhammad Naghman Choudhry, ${ }^{1, *}$ Zafar Ahmad $^{2}$ and Rajat Verma ${ }^{2}$ \\ ${ }^{\prime}$ Royal Manchester Children's Hospital, Oxford Road, Manchester, M13 9WL, United Kingdom \\ ${ }^{2}$ Orthopaedic Research Unit, Addenbrookes Hospital, Box 180 Cambridge, CB2 OQQ, United Kingdom
}

Received: May 30, 2015

Revised: September 06, 2015

Accepted: September 11, 2015

\section{Abstract: \\ Background:}

Scoliosis refers to deviation of spine greater than 10 degrees in the coronal plane. Idiopathic Scoliosis is the most common spinal deformity that develops in otherwise healthy children. The sub types of scoliosis are based on the age of the child at presentation. Adolescent idiopathic scoliosis (AIS) by definition occurs in children over the age of 10 years until skeletal maturity.

\section{Objective:}

The objective of this review is to outline the features of AIS to allow the physician to recognise this condition and commence early treatment, thereby optimizing patient outcome.

\section{Method:}

A thorough literature search was performed using available databases, including Pubmed and Embase, to cover important research published covering AIS.

\section{Conclusion:}

AIS results in higher incidence of back pain and discontent with body image. Curves greater than 50 degrees in thoracic region and greater than 30 degrees in lumbar region progress at a rate of 0.5 to 1 degree per year into adulthood. Curves greater than 60 degrees can lead to pulmonary functional deficit. Therefore once the disease is recognized, effective treatment should be instituted to address the deformity and prevention of its long-term sequelae.

Keywords: Adolescent, deformity, scoliosis, spine.

\section{INTRODUCTION}

Scoliosis has been plaguing medical practitioners for thousands of years. In 3,500 BC ancient Hindu texts describe a woman whose back was deformed in three different places. It took the intervention of the Hindu God Krishna to straighten her, by putting his feet on hers and pulling her up by the chin [1]. Hippocrates himself tried to treat patients by strapping them to a traction [2]. Since then, scoliosis treatment has been revolutionized by the introduction of: braces by Pare in 1510, the posterior fusion by Hibbs in the early 1900s and more significantly in the recent past, the spinal instrumentation system developed by Harrington [3].This article aims to provide an overview of this condition so that the physicians may become more aware of how to detect it and how the condition is managed.

\footnotetext{
* Address correspondence to this author at the Royal Manchester Children's Hospital, Oxford Road, Manchester, M13 9WL, United Kingdom; Tel: 0044 7931146389; Fax: 0044161 7010636; Email: mchoudhry@doctors.org.uk
} 
Table 1. Classification of scoliosis.

\begin{tabular}{|l|l|}
\hline Congenital: Failure of formation, Failure of segmentation & Idiopathic: Infatile (0-3 years), Juvenile (3-10 years), Adolescent (10+ years) \\
\hline Neuromuscular: & Others: Neurofibromatosis, Mesenchymal \\
1) Myopathic Arthrogryposis, Muscular dystrophy & (Marfan's, Ehler-Danlos), Traumatic, Tumors, Osteochondrodystrophies \\
2) Neuropathic Upper Motor Neurone, Lower Motor Neurone, & \\
Dysautonomia & \\
\hline
\end{tabular}

Table 2. Secondary causes of scoliosis and relevant symptoms.

\begin{tabular}{|c|c|}
\hline Neuologic Disorders & Sign and Symptoms \\
\hline $\begin{array}{l}\text { Syringomyelia } \\
\text { Tethered cord syndrome } \\
\text { Spinal tumor }\end{array}$ & $\begin{array}{l}\text { Weakness, sensory changes, problems of balance, gait and coordination, as well as bowel and bladder } \\
\text { difficulties such as incontinence }\end{array}$ \\
\hline Neurofibromatosis & café-au-lait spots or axillary freckles \\
\hline Friedreich's ataxia & Gait disturbance to speech problems. Heart disease and diabetes \\
\hline Familial dysautonomia (Riley-Day syndrome) & Insensitivity to pain, instability to produce tears, poor growth and labile blood pressure \\
\hline Werdnig-Hoffmann disease & Inefficiency of respiratory system - and pneumonia-induced respiratory failure \\
\hline Duchenne muscular dystrophy & Progressive proximal muscle weakness of the legs and pelvis associated with a loss of muscle mass \\
\hline Cerebral palsy & Spasticities, spasms, unsteady gait, problems with balance and decreased muscle mass \\
\hline Poliomyelitis & $\begin{array}{l}\text { Flaccid paralysis in one or more limbs with decreased or absent tendon reflexes, without sensory or } \\
\text { cognitive loss. }\end{array}$ \\
\hline Charcot-Marie-Tooth disease & High- arched or cavus feet \\
\hline \multicolumn{2}{|l|}{ Connective Tissue Disorders } \\
\hline Ehlers-Danlos Syndrome & Marked ligamentous hyperlaxity and or skin elasticity \\
\hline Marfan syndrome & Tall, long fingers, increased arm span to height ratio and cardiac abnormalities \\
\hline Homocystinuria & Family history, seizures, Marfanoid habitus, seizures and mental retardation \\
\hline \multicolumn{2}{|l|}{ Musculoskeletal } \\
\hline Leg length discrepancy & Previous injury/fractures \\
\hline Developmental dysplasia of the hip & Family history, positive Ortolani and Barlow tests \\
\hline Osteogenesis imperfecta & Family history, multiple fractures, loose joints and respiratiory problems \\
\hline Klippel-Feil syndrome & Spina bifida, cleft palate, short stature and cardiorespiratory problems \\
\hline
\end{tabular}

\section{DEFINITION}

Scoliosis comes from the Greek Word "skoliosis" meaning crooked. It is a complex three-dimensional deformity of the spine characterised by a lateral deviation of at least 10 degrees with a rotation of the vertebra and usually associated with reduction of normal kyphotic curvature of the spine (Hypokyphosis) [4]. It can be classified into congenital, neuromuscular, and idiopathic (See Table 1). As the behaviour and management of these conditions are potentially different [3], we will cover the most common of the three classifications - adolescent idiopathic scoliosis.

\section{CLASSIFICATION OF SCOLIOSIS}

Idiopathic scoliosis is classified based on the age of the child at presentation. It can be divided in early onset (age 5 7) and late onset (age 7 till maturity). However, the Growing Spine Committee of the Scoliosis Research Society, and the Pediatric Orthopaedic Society of North America have all endorsed the definition of early onset scoliosis as scoliosis with onset less than the age of ten years, regardless of aetiology [5].

Idiopathic scoliosis can also be divided into 3 phases: infantile, juvenile and adolescent (see Table 1) [6].

Accordingly, there are several classifications for scoliosis used by professionals to help in management and to predict outcomes for patients. The one that is currently used for surgical planning is the Lenke Classification [7]. The Lenke Classification (Lenke et al. 2001 JBJS) has three components: (1) Curve patterns (2) Lumbar spine modifiers (3) Sagittal thoracic modifier [7]. This classification was introduced to help surgeons in determining the extent of spinal instrumentation. Classification systems are still evolving to produce more accurate predictions and descriptions of scoliosis.

Over the past years, several articles have been published on the evaluation and potential classification of Adolescent idiopathic scoliosis (AIS) using three-dimensional (3D) terminology and techniques. CT scan and MRI could be used to assess the spine in 3D [8]. Thoracic AIS deformity involves alterations in the coronal, sagittal and axial planes. The 
operative goal is to recreate the normal 3- dimensional position of the thoracic region. In the near future, this type of 3D evaluation and classification will become an integral part in the treatment decisions and comparisons of operative treatment [8].

\section{EPIDEMIOLOGY AND PATHOLOGY}

The overall prevalence of AIS is $0.47 \%$ to $5.2 \%$ in the current literature [ 9 - 12]. AIS commonly affect girls with a female to male ratio of $1.5: 1$ to $3: 1$. This ratio increases substantially with increasing age [12, 13]. 90\% of the presentation will show a right-sided thoracic curve (See Fig. 1).

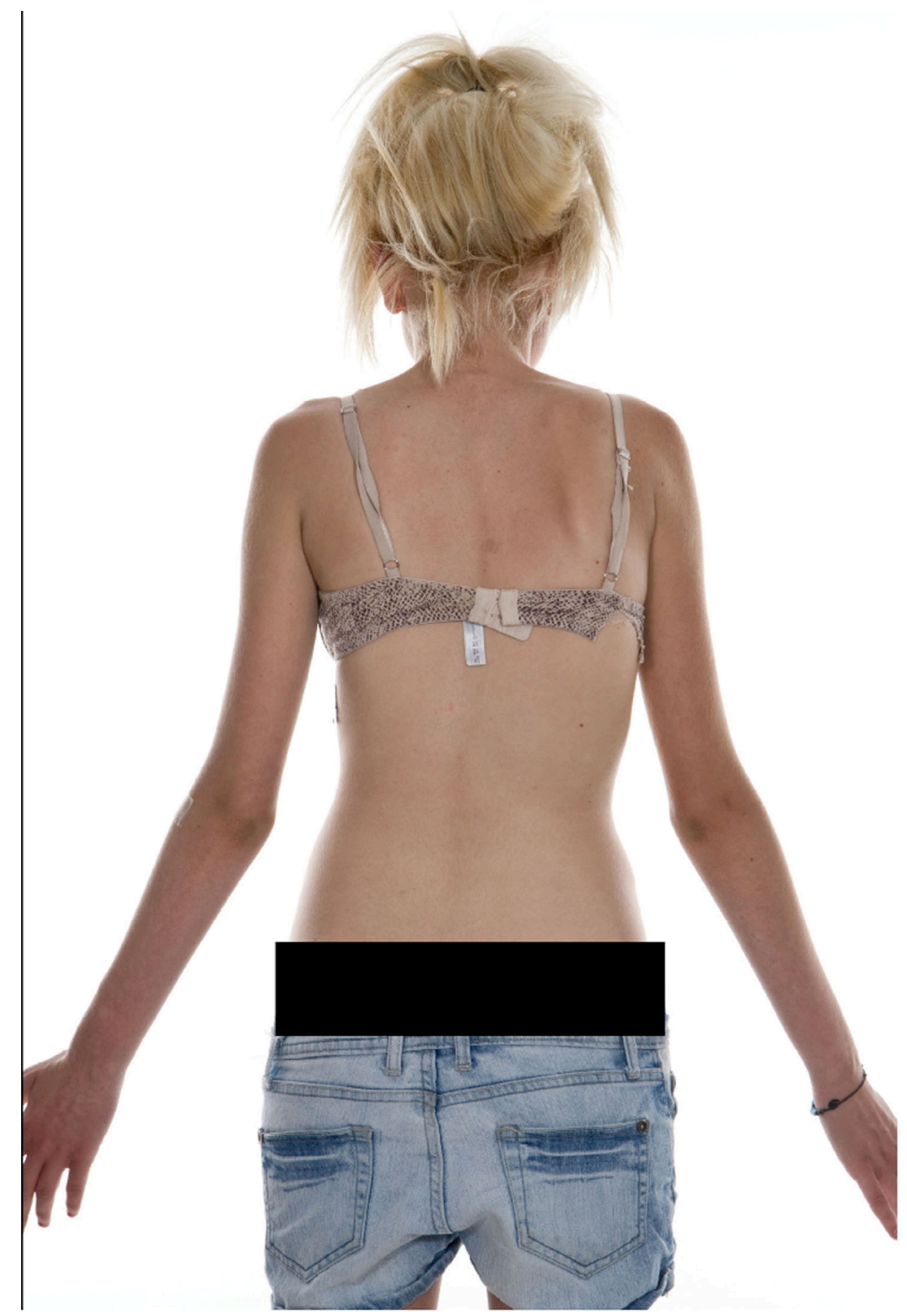

Fig. (1). Clinical appearance of an adolescent girl with a right thoracic curve.

In $80 \%$ of cases of scoliosis the cause is largely unknown. It may be related to a central nervous system, proprioception, or homeostasis disorder (see Table 1). A genetic link has been suggested, as 1 in 4 patients with scoliosis have a relative with the condition, but the inheritance pattern is variable [4]. A primary muscle disorder has been postulated as a possible aetiology of idiopathic scoliosis. Presently the cause is thought to be multifactorial with genetic predisposing factors, including Metabolic (based on melatonin studies), Hormonal and Biomechanical factors [4, 13]. 


\section{NATURAL HISTORY}

The logical approach to a child presenting with scoliosis is to first rule out any non-idiopathic aetiology. Second is to determine if the idiopathic curve will progress and create potential long-term complications.

A combination of following individual factors is used to predict curve progression: age at presentation (future growth potential), gender (including menarche status) and the magnitude of the curve at presentation.

Evaluation of growth potential is assessed using the Risser grading (Fig. 2). Risser sign refers to the amount of calcification of the human pelvis as a measure of maturity. On a scale of 1 to 5 , it is based on the measure of progression of ossification on a pelvic X-ray. Grade 5 indicating skeletal maturity is reached [14]. In all cases, females have a risk of curve progression 10 times higher than males [14].

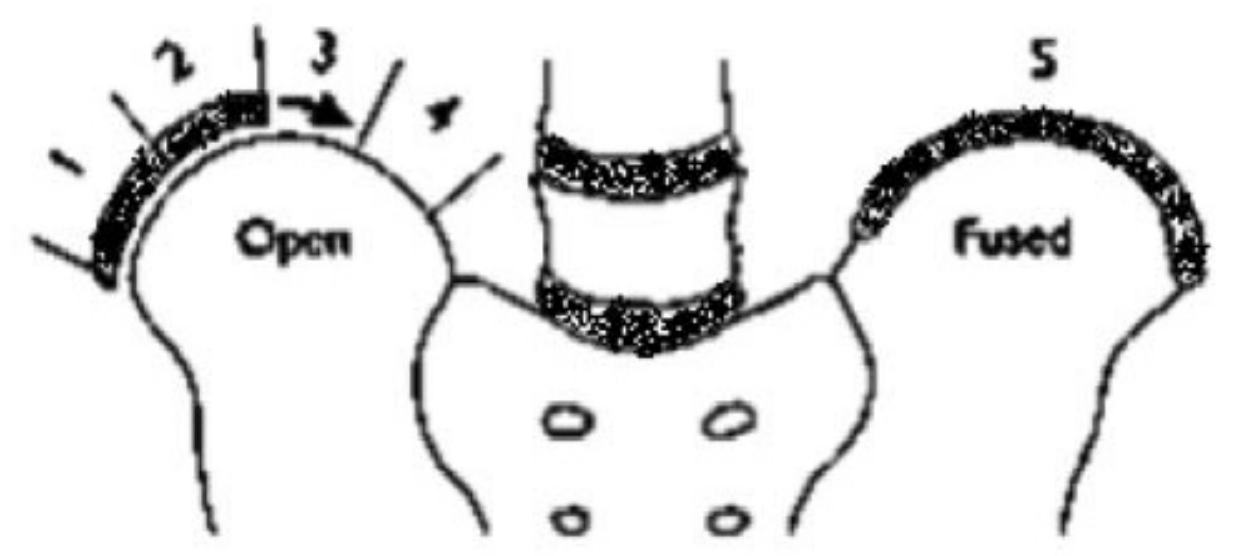

Fig. (2). This figure demonstrates Risser grading from zero to 5. Grading depends on the degree of bony fusion of the iliac apophysis. Grade zero signifies no ossification. Grade 5 signifies complete bony fusion.

The age of maximum velocity of growth is called the age at peak height velocity (PHV). PHV is the best predictor of curve progression. In females it occurs before Risser 1 and just before menarche (girls usually reach skeletal maturity 1.5 years after menarche) $[14,15]$. If curve is greater than $30^{\circ}$ before PHV there is a strong likelihood of the need for surgery [15]. The greater the growth potential and the larger the curve, the greater is the likelihood of curve progression [14].

There are several other classification/systems that can be utilized to assess skeletal maturity and hence curve progression. The Tanner-Whitehouse 3 assessments, which assesses the skeletal maturity based on radiographic evaluation of the epiphyses of the distal radius, distal ulna, and small hand bones. These 3 assessments were simplified and used to create a skeletal scoring system to estimate scoliosis behaviour [16]. The simplified Sanders Skeletal Maturity Staging System is based on the progressive growth and subsequent fusion of epiphyses of small long bones of hand. It identifies 8 stages of progression from 'juvenile slow' to 'mature'. This classification compares the Cobb angle and digital skeletal age to predict the likelihood of curve progression $[17,18]$.

According to natural history studies, the curve magnitude of $25^{\circ}$ at presentation may be predictive of a greater risk of curve progression. Most curves of greater than $50^{\circ}$ continue to progress [14]. Curvatures $<10^{\circ}$ have little potential for progression and are viewed as a variation of normal [14].

Although the above risk factors are widely used by spine specialists, the relative importance of each factor and how they may interact is as yet not defined. There is no succinct evidence in previous studies that these factors accurately predict curve progression. Therefore, there is still no consensus or definitive guidelines established in the prediction of curve progression and hence, when to institute treatment for each child [14].

\section{PROGNOSIS}

Infantile scoliosis or early onset scoliosis is rare and resolves spontaneously in most cases [14]. The ones that do 
progress require complex treatment. If left untreated this may be associated with long-term pulmonary complications, which is not commonly seen in AIS [19].

Traditionally, scoliosis has been described as a non-painful condition. One study [20] from the USA studied more than 2400 patients with scoliosis and found that $23 \%$ of them (560 of 2442 patients) had back pain at the time of presentation. An underlying pathologic condition was identified in 9\% (48 of 560) of the patients with back pain, including mainly spondylolysis and spondylolisthesis and one case of intraspinal tumour. It would seem that pain is more frequently associated with scoliosis than previously thought [20]. An aggressive workup has been recommended for patients who present with painful scoliosis.

However, most with AIS continue to have normal relationships, have children and work in the community. They continue to do well for at least 20 years past skeletal maturity [19].

\section{PRESENTATION}

The vast majority of patients initially present due to a deformity. This may be a perception of asymmetry about the shoulders, waist, or rib cage noticed by the patient, a family member, the primary care physician or a school nurse. Asymmetry of breasts might be the first thing noticed by female patients.

\section{History and Examination}

The patient's history should include age, birth history, developmental milestones, family history, assessment of physiologic maturity (e.g. menarche) and presence or absence of pain. Particular note should be made regarding menarchal status as this has a significant influence on curve progression. Physical examination should include a baseline assessment of curve patterns, shoulder levels, waist asymmetry, and pelvic tilt. Rib rotational deformity (rib hump) should be evaluated by performing the Adam forward bend test. A positive test would reveal a rib hump on the convex side of the curve.

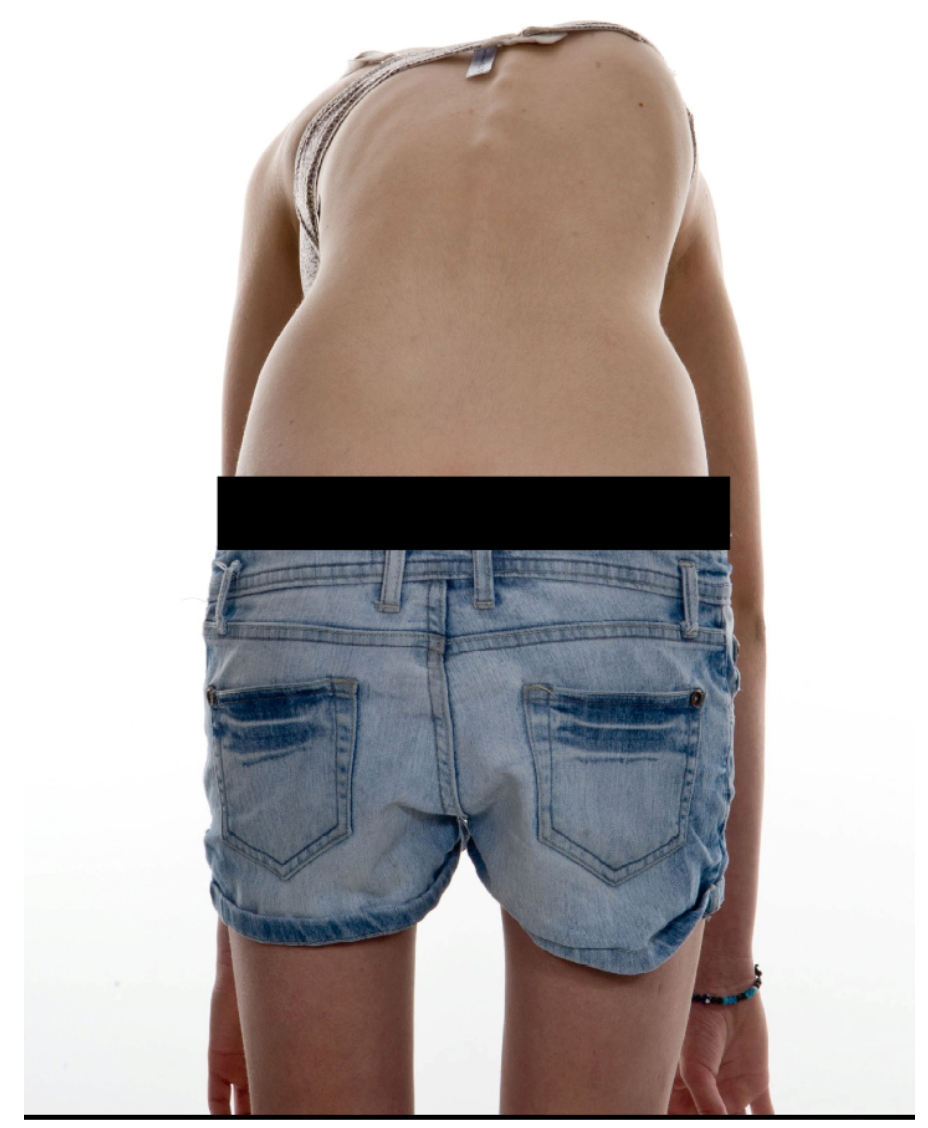

Fig. (3). Adams forward-bending test. Here a patient is viewed from behind and asked to bend forward until the spine is horizontal. Note the right side of the back appears higher than the left. 
Adams forward-bending test has been found to be an effective screening tool (See Fig. 3). There is currently no screening program in the UK. A measurement of 7 degrees rotatory asymmetry determined using a scoliometer is generally used as the cut-off point for referral for evaluation of scoliosis. A 7 degree measurement by scoliometer correlates with a Cobb angle of 20 degrees [21].

Secondary causes of scoliosis should be ruled out. Therefore, full neurological and musculoskeletal examination is necessary (see Table 2). Presence of the following will place the curve in a non-idiopathic category- midline skin defects, spina bifida, meningomyelocele, and cafe-au-lait spots (in cases of neurofibromatosis). A forward bending sitting test can eliminate leg length inequality as a postural cause of scoliosis. Foot deformities, such as cavovarus, can indicate the presence of an underlying neural axis abnormality. The presence of asymmetric abdominal reflexes should prompt the clinician to consider a magnetic resonance imaging (MRI) scan to rule out a syringomyelia. Other red flags include severe pain (night pain), untoward stiffness, deviation to one side during the forward bend test (known a list), sudden rapid progression in a previously stable curve, extensive progression in a patient after skeletal maturity and abnormal neurologic findings.

The most typical presentation of AIS is a right-sided thoracic curve in a female patient, which is pain less, without any abnormal neurological findings.

Curves that are greater than 90 degrees are rare, but associated with pain and decreased self-image [21].

\section{INVESTIGATIONS}

X-ray imaging includes standing posterior-anterior to measure the degree of the curve using the Cobb method (Figs. 4a \& 5). A standardized lateral radiograph to appreciate any sagittal abnormality (Fig. 4b). These whole spine $x$-rays should include pelvis to assess the ossification of iliac crest in order to evaluate the Risser's sign (growth status). Obtain bending films to assess the flexibility of the curve (Fig. 6).

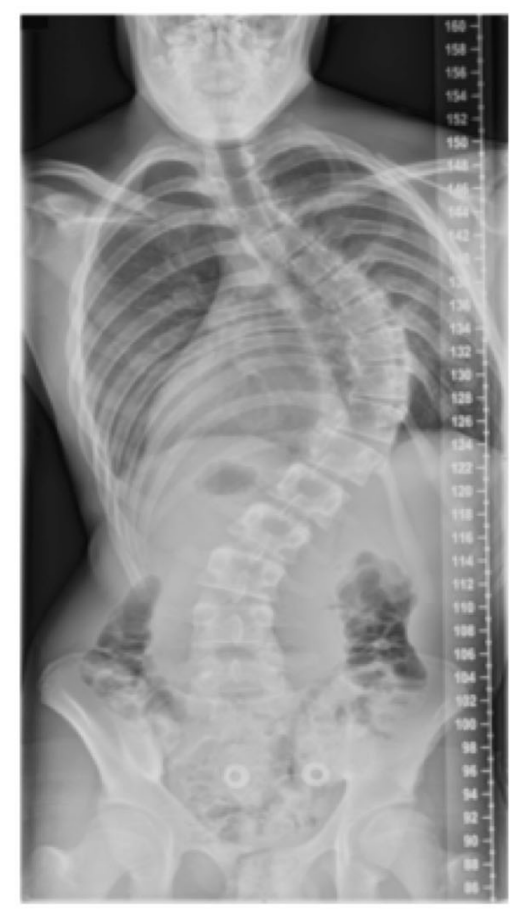

(a)

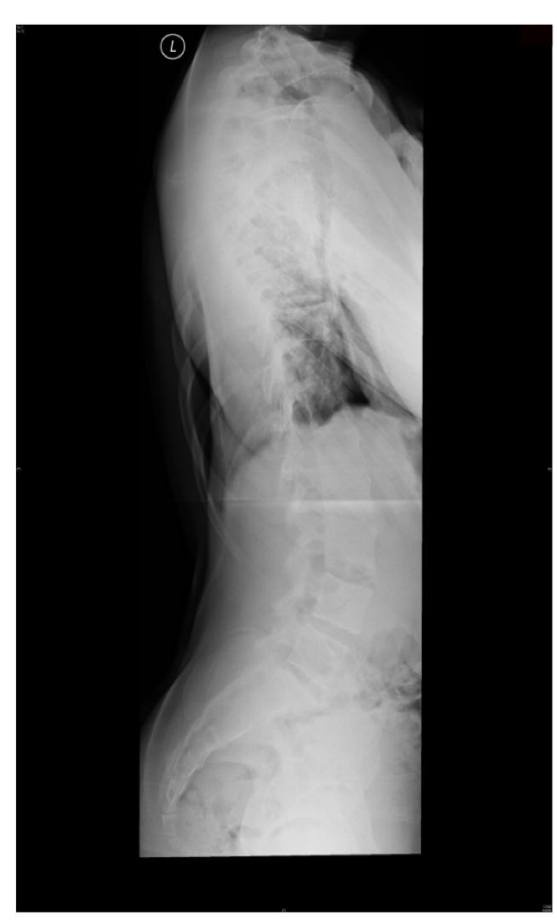

(b)

Fig. (4). a Posterio-anterior standing radiograph showing right thoracic curve. b Lateral standing radiograph. 


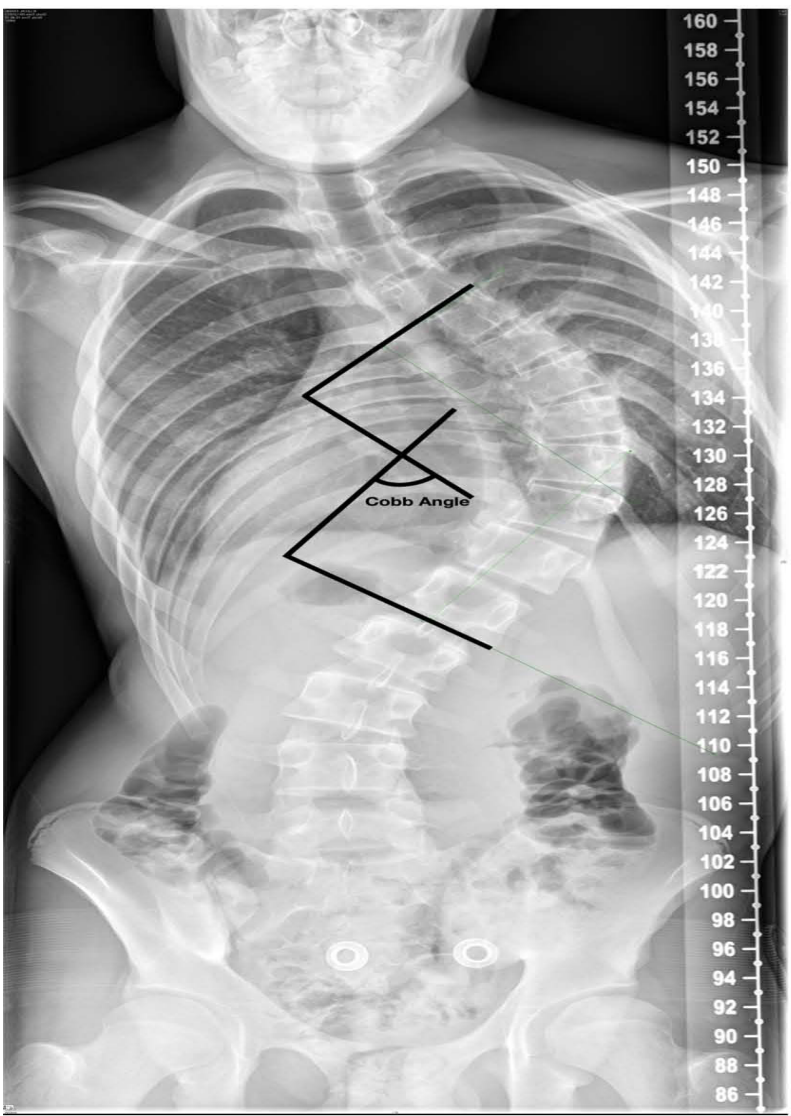

Fig. (5). The Cobb method of measuring the degree of scoliosis. Choose the most tilted vertebrae above and below the apex of the curve. The angle between intersecting line drawn perpendicular to the superior endplate of the top vertebrae and the inferior endplate of the bottom verterbrae is the Cobb angle.
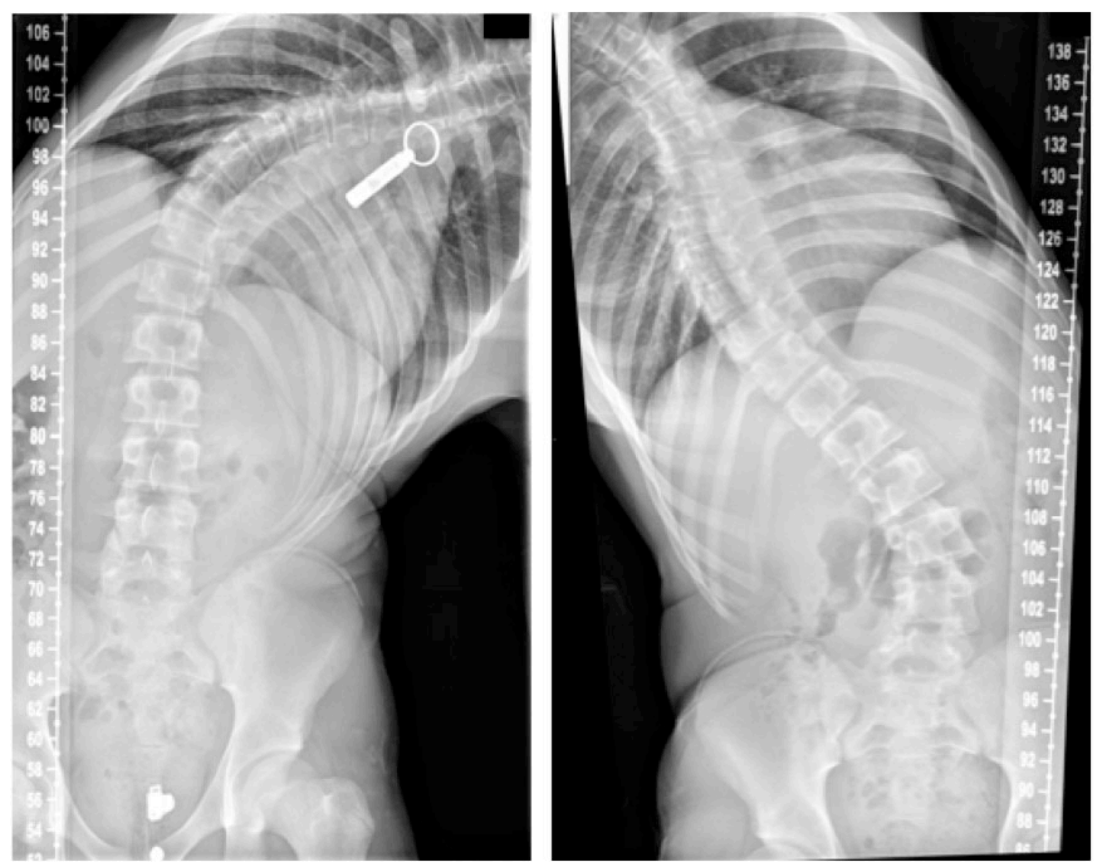

Fig. (6). Bending radiographs performed here to assess the stiffness of the curve. The degree of correction is a measure of curve flexibility. This assists in planning the level of surgery required and is predictive of correction possibile with surgery. 
It is usually indicated to exclude a Chiari I malformation, a syrinx, tumour, neurofibromatosis, and cord tethering. MRI scan is mandatory in patients who present with a very rapid curve progression, back pain, neurologic deficiency, neck stiffness, and severe unexplained headaches. Similarly when clinical findings such as ataxia or cavus feet are present, these patients should also be considered for MRI scan. Pulmonary function test can be considered in large curves [22].

3D reconstructions of the spine have been used in clinical studies for assessing scoliosis. It adds extra detail on the curvature and anatomy of the scoliosis, which subsequently helps with classification, pre-op planning and monitoring progression [22].

\section{TREATMENT}

The main treatment options for scoliosis can be summarised by the three Os: Observation, Orthosis (bracing), and Operative treatment. The selection of the best treatment is based on the maturity of the patient (age, menarchal status, Risser grading of Iliac apophysis), location, severity and risk of progression of the curvature [23]. A common protocol used to guide treatment is: to observe patients with curves of less than 25 degrees, to brace patients between 25-45 degrees, and to consider surgery on patients with curves of greater than 45 degrees [23].

\section{Observation}

When the curvature is less than 25 degrees, patient can be observed on a 6 to 12 monthly basis with clinical and radiological follow up. These patients are provided with appropriate information and directed to the Scoliosis Research Society website [24].

When discussing surgery with patients, the natural history of AIS needs to be taken into account. A recent literature review looked at studies concerning long-term outcome in patients with AIS that had received no treatment [25]. The literature review showed that single thoracic curves of $50^{\circ}-75^{\circ}$ progress $0.73^{\circ}$ year over a 40 -year period [25]. It concluded that most individuals with AIS and moderate curve size around maturity function well and lead an acceptable life in terms of work and family. When compared to the healthy population there weren't any apparent disadvantages in their social function, childbearing, and marriage. Some patients with larger curves (greater than 110) have pulmonary problems, but this does not result in increased mortality [25].

\section{Bracing}

For curves between 25 and 45 degrees below the level of T8 in general, and there is risk of curve progression. Bracing should be considered, so that the curve does not progress with time. In past braces were uncomfortable and embarrassing. Now thoracolumbar braces come in a variety of shapes, size and padding (Milwaukee brace, Boston brace and the Charleston brace). A meta-analysis by Row et al. [26] has shown a 93\% success rate for bracing 23 hours per day. Although bracing has been shown to be effective, compliance is poor and it is associated with psychological stress [27]. It is important to counsel adolescents and their parents that bracing does not correct scoliosis but may prevent significant progression of the spinal curvature. Use of a brace is continued until the patient reaches Risser grade 4 or 5. Although bracing is moderately successful, its efficacy is not fully proven due to lack of strong evidence [28].

\section{Surgical Treatment}

Surgical treatment is indicated to halt curve progression (especially curves beyond 45) and improve cosmetic appearance. The main goal of surgery is to achieve correction of deformity including rotation, a fusion of the structural deformity of the spine, which will prevent further progression. This subsequently aims to improve spinal alignment and balance. The selection of specific approach to surgery therefore depends on the curvature and location of the spinal curve. A thoracic curve with minimal lumbar curve is treated with a posterior thoracic fusion using instrumentation (See Fig. 7).

There are several approaches that can be used for AIS surgery. These include: anterior only (open or thoracoscopic), combined anterior/posterior or posterior only. Open Anterior surgery has the advantage of preventing crankshaft effect in skeletally immature patients. There is increased flexibility and allows for correction of very rigid curves. It reduces the number of vertebrae needed for fusion hence preserves spinal mobility [29]. However, with anterior approach the impact of chest wall violation on pulmonary function is well documented [29]. 


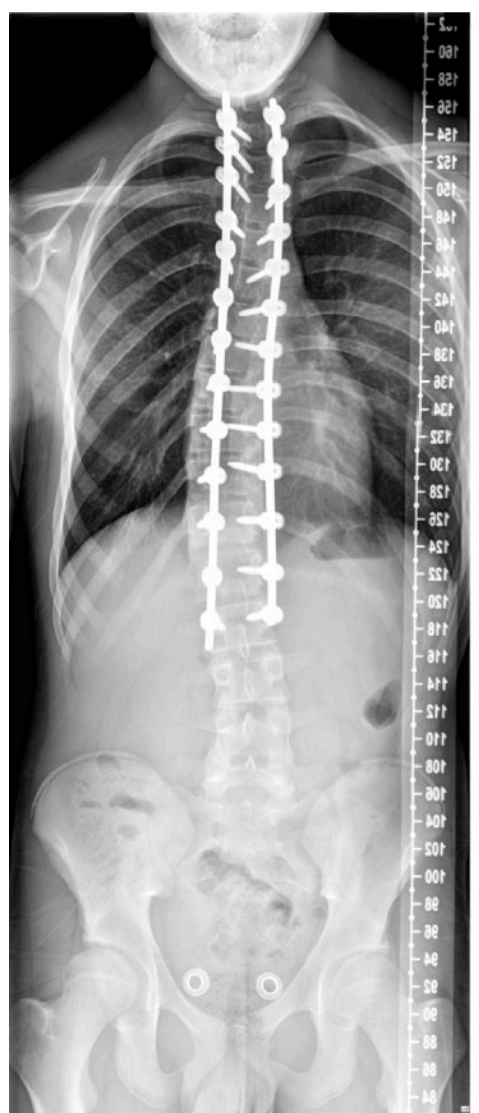

(a)

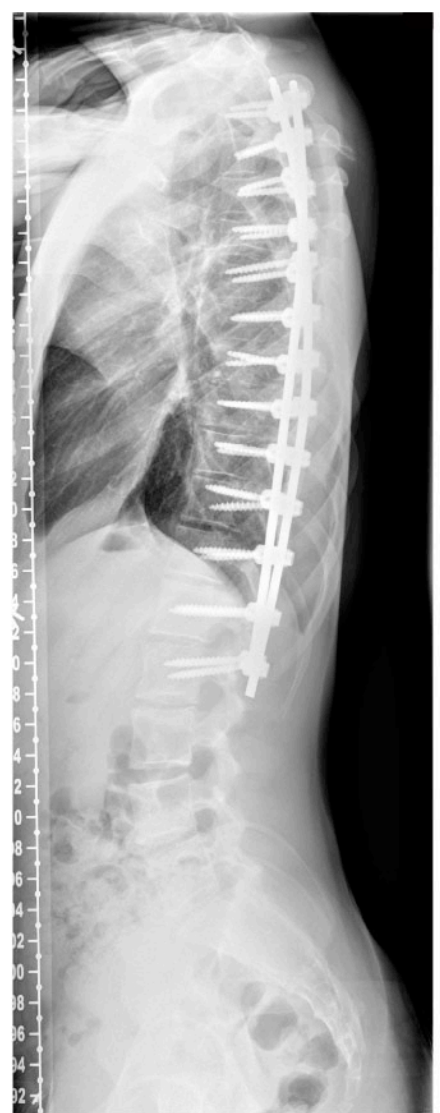

(b)

Fig. (7). Postoperative posterio-anterior and lateral radiographs demonstrating a satisfactory coronal plane correction (compare to pre-operative radiographs in Fig. (4)

Anterior thoracoscopic instrumentation is another option, which provides similar correction with good cosmetic appearance, reduced blood loss and faster recovery of pulmonary function. However, it is associated with a high risk of instrument pull-out and pseudoarthrosis and pulmonary complications. Izatt et al. [30] prospectively reviewed 100 patients undergoing thoracoscopic scoliosis surgery for AIS. The patients reported good post-operative patient reported outcome scores [30]. Newton et al. [31] reported similar good patient satisfaction scores in 41 patients undergoing anterior thoracoscopic scoliosis surgery for thoracic scoliosis. However, they did report 3 patients with rod failure and 3 patients required a surgical revision with posterior spinal instrumentation and fusion [31].

Anterior release followed by posterior instrumented fusion allows better correction of severe AIS, but these patients still have the associated risks of anterior approach along with the morbidity of having to undergo 2 procedures.

The use of anterior only or combined anterior and posterior approaches for large thoracic curves has declined the last 10 years. The anterior approach led to postoperative complications especially diminished pulmonary function. Since the advent of thoracic pedicle screw fixation, the posterior only approach is widely used and is associated with better correction rates and decreased complications [8]. Hence, the treatment of a lumbar or thoraco-lumbar curve is widely performed through a posterior only approach, except in few selected centres who continue to use anterior open/thoracoscopic approach [8].

Several studies have examined the efficacy of posterior-only fusion for the treatment of severe thoracic AIS. Luhmann and Lenke [29] compared combined treatment (anterior and posterior fusion) with posterior fusion only in severe AIS. They concluded that the patients treated with pedicle screw-only instrumentation presented similar results to those who underwent combined treatment (60.7 vs. $58.5 \%$ ) [29].

A similar study by Dobbs et al. assessed results of spinal fusion for AIS curves $>90$ degrees [30]. They found no statistically significant differences between the groups (combined anterior/posterior spinal fusion or a posterior spinal fusion alone) for gender, age, number of levels fused, preoperative coronal/sagittal Cobb measurements, coronal curve 
flexibility, or amount of postoperative coronal Cobb correction [30].

The treatment of structural double curves (i.e. thoracic and lumbar curves with a bending Cobb of $>25$ degrees) is instrumented fusion of both curves. Costoplasty may be employed to correct any residual rib humps.

Postoperatively patients normally stay inpatient for up to 2 weeks requiring analgesia and physiotherapy. Surgical complications are minimised with modern instrumentations and by perioperative spinal cord monitoring [32].

With constant development in newer techniques and instrumentation, again there is lack of long-term results [32]. There are results from a twenty-one year follow up study of patients with Harringtion instrumentation and arthrodesis. Twenty-one years after the operation, the patients were functioning quite well compared with the control subjects [32]. A randomized controlled trial (RCT) is long overdue to see the unknown long-term effects of surgery. Due to the presence of evidence to support conservative treatments, a plan to compose a RCT for conservative treatment options seems unethical [33].

\section{CONCLUSION}

For the spinal surgeon, idiopathic scoliosis is one of the most frequent presentations of spinal deformity in the paediatric clinic. This condition results in higher incidence of back pain and discontent with body image. Curves greater than 50 degrees in thoracic region and greater than 30 degrees in lumbar region progress at a rate of 0.5 to 1 degree per year into adulthood. Curves greater than 60 degrees can lead to pulmonary functional deficit. Therefore once the disease is recognized, effective treatment should be instituted to address the deformity and prevention of its long-term sequelae.

\section{KEY LEARNING POINTS}

Scoliosis is a complex three-dimensional deformity of the spine characterised by a lateral deviation of at least 10 degrees associated with a rotational component.

The most common presentation is adolescent idiopathic scoliosis.

Early recognition is key to minimising morbidity and mortality.

Management options can be divided into the three O's: Observation, Orthosis, Operation

\section{LIST OF ABBREVIATIONS}

$\begin{array}{lll}\text { 3D } & = & \text { Three dimension } \\ \text { AIS } & = & \text { Adolescent idiopathic scoliosis } \\ \text { MRI } & = & \text { Magnetic resonance imaging } \\ \text { PHV } & = & \text { Peak height velocity } \\ \text { RCT } & = & \text { Randomized controlled trial }\end{array}$

\section{CONFLICT OF INTEREST}

The authors confirm that this article content has no conflict of interest.

\section{ACKNOWLEDGEMENTS}

Declared none.

\section{REFERENCES}

[1] Kumar K. Spinal deformity and axial traction. Spine 1996; 21: 653-5. [http://dx.doi.org/10.1097/00007632-199603010-00024]

[2] Le Vay D. The history of orthopaedics: An account of the study and practice of orthopaedics from the earliest times to the modern era. US: Parthenon Publishing 1990.

[3] Boos N, Aebi M. Spinal disorders: fundamentals of diagnosis and treatment. Germany: Springer 2008. [http://dx.doi.org/10.1007/978-3-540-69091-7]

[4] Miller MD, Thompson SR, Hart J. Review of orthopaedics. US: Elsevier Health Sciences 2012.

[5] El-Hawary R, Akbarnia BA. Early onset scoliosis-time for consensus. Spine Deform 2015; 2: 105-6. [http://dx.doi.org/10.1016/j.jspd.2015.01.003]

[6] Fletcher ND, Bruce RW. Early onset scoliosis: current concepts and controversies. Curr Rev Musculoskelet Med 2012; 5: 102-10. 
[http://dx.doi.org/10.1007/s12178-012-9116-0]

[7] Lenke LG, Betz RR, Harms J, et al. Adolescent idiopathic scoliosis: a new classification to determine extent of spinal arthrodesis. J Bone Joint Surg Am 2001; 83-A: 1169-81.

[8] Lenke LG. What's new in the surgical care of Adolescent Idiopathic Scoliosis (AIS). ArgoSpine News J 2012; 24: 62-6. [http://dx.doi.org/10.1007/s12240-012-0043-0]

[9] Wong HK, Hui JH, Rajan U, Chia HP. Idiopathic scoliosis in Singapore schoolchildren: a prevalence study 15 years into the screening program. Spine 2005; 30: 1188-96. [http://dx.doi.org/10.1097/01.brs.0000162280.95076.bb]

[10] Cilli K, Tezeren G, Taş T, et al. School screening for scoliosis in Sivas, Turkey. Acta Orthop Traumatol Turc 2009; 43: 426-30. [http://dx.doi.org/10.3944/AOTT.2009.426]

[11] Soucacos PN, Soucacos PK, Zacharis KC, Beris AE, Xenakis TA. School-screening for scoliosis. A prospective epidemiological study in northwestern and central Greece. J Bone Joint Surg Am 1997; 79: 1498-503.

[12] Konieczny MR, Senyurt H, Krauspe R. Epidemiology of adolescent idiopathic scoliosis. J Child Orthop 2013; 7: 3-9. [http://dx.doi.org/10.1007/s11832-012-0457-4]

[13] Stirling AJ, Howel D, Millner PA, Sadiq S, Sharples D, Dickson RA. Late-onset idiopathic scoliosis in children six to fourteen years old. a cross-sectional prevalence study. Journal of Bone \& Joint Surgery 1996; 78: 1330-6.

[14] Wong H-K, Tan K-J. The natural history of adolescent idiopathic scoliosis. Indian J Orthop 2010; 44: 9. [http://dx.doi.org/10.4103/0019-5413.58601]

[15] Sanders JO, Browne RH, McConnell SJ, Margraf SA, Cooney TE, Finegold DN. Maturity assessment and curve progression in girls with idiopathic scoliosis. J Bone Joint Surg Am 2007; 89: 64-73. [http://dx.doi.org/10.2106/JBJS.F.00067]

[16] Greiner KA. Adolescent idiopathic scoliosis: radiologic decision-making. Am Fam Physician 2002; 65: 1817-22.

[17] Sanders JO, Khoury JG, Kishan S, et al. Predicting scoliosis progression from skeletal maturity: a simplified classification during adolescence. J Bone Joint Surg Am 2008; 90: 540-53. [http://dx.doi.org/10.2106/JBJS.G.00004]

[18] Sitoula P, Verma K, Holmes L Jr, et al. Prediction of curve progression in idiopathic scoliosis: validation of the sanders skeletal maturity staging system. Spine 2015; 40: 1006-13.

[http://dx.doi.org/10.1097/BRS.0000000000000952]

[19] Cordover AM, Betz RR, Clements DH, Bosacco SJ. Natural history of adolescent thoracolumbar and lumbar idiopathic scoliosis into adulthood. J Spinal Disord Tech 1997; 10: 193-6.

[20] Ramirez N. Johnston CE, Browne RH. The prevalence of back pain in children who have idiopathic scoliosis. J Bone Joint Surg 1997.

[21] Bunnell WP. An objective criterion for scoliosis screening. J Bone Joint Surg Am 1984; 66: 1381-7.

[22] Kadoury S, Labelle H. Classification of three-dimensional thoracic deformities in adolescent idiopathic scoliosis from a multivariate analysis. Eur Spine J 2012; 21: 40-9.

[http://dx.doi.org/10.1007/s00586-011-2004-2]

[23] Fusco C, Donzelli S, Lusini M, Salvatore M, Zaina F, Negrini S. Low rate of surgery in juvenile idiopathic scoliosis treated with a complete and tailored conservative approach: end-growth results from a retrospective cohort. Scoliosis 2014; 9: 12. [http://dx.doi.org/10.1186/1748-7161-9-12]

[24] Weiss HR, Weiss G, Petermann F. Incidence of curvature progression in idiopathic scoliosis patients treated with scoliosis in-patient rehabilitation (SIR): an age- and sex-matched controlled study. Pediatr Rehabil 2003; 6: 23-30. [http://dx.doi.org/10.1080/1363849031000095288]

[25] Danielsson AJ. Natural history of adolescent idiopathic scoliosis: a tool for guidance in decision of surgery of curves above $50^{\circ}$. J Child Orthop 2013; 7: 37-41.

[http://dx.doi.org/10.1007/s11832-012-0462-7]

[26] Rowe DE, Bernstein SM, Riddick MF, Adler F, Emans JB, Gardner-Bonneau D. A meta-analysis of the efficacy of non-operative treatments for idiopathic scoliosis. J Bone Joint Surg Am 1997; 79: 664-74.

[27] MacLean WE, Green NE, Pierre CB, Ray DC. Stress and coping with scoliosis: psychological effects on adolescents and their families. J Pediatr Orthop 1989; 9: 257-61.

[http://dx.doi.org/10.1097/01241398-198905000-00001]

[28] Betz RR, Ranade A, Samdani AF, et al. Vertebral body stapling: a fusionless treatment option for a growing child with moderate idiopathic scoliosis. Spine 2010; 35: 169-76. [http://dx.doi.org/10.1097/BRS.0b013e3181c6dff5]

[29] Sud A, Tsirikos AI. Current concepts and controversies on adolescent idiopathic scoliosis: Part II. Indian J Orthop 2013; 47: $219-29$. [http://dx.doi.org/10.4103/0019-5413.111493]

[30] Izatt MT, Adam CJ, Labrom RD, Askin GN. The relationship between deformity correction and clinical outcomes after thoracoscopic 
scoliosis surgery: a prospective series of one hundred patients. Spine 2010; 35: E1577-85.

[http://dx.doi.org/10.1097/BRS.0b013e3181d12627]

[31] Newton PO, Upasani VV, Lhamby J, Ugrinow VL, Pawelek JB, Bastrom TP. Surgical treatment of main thoracic scoliosis with thoracoscopic anterior instrumentation. Surgical technique. J Bone Joint Surg Am 2009; 91(Suppl. 2): 233-48.

[32] Dickson JH, Erwin WD, Rossi D. Harrington instrumentation and arthrodesis for idiopathic scoliosis. A twenty-one-year follow-up. J Bone Joint Surg Am 1990; 72: 678-83.

[33] Weiss HR, Goodall D. The treatment of adolescent idiopathic scoliosis (AIS) according to present evidence. A systematic review. Eur J Phys Rehabil Med 2008; 44: 177-93.

(C) Choudhry et al.; Licensee Bentham Open.

This is an open access article licensed under the terms of the Creative Commons Attribution-Non-Commercial 4.0 International Public License (CC BY-NC 4.0) (https://creativecommons.org/licenses/by-nc/4.0/legalcode), which permits unrestricted, non-commercial use, distribution and reproduction in any medium, provided the work is properly cited. 